\title{
Olfactory dysfunction in Parkinson's disease
}

\author{
C H Hawkes, B C Shephard, S E Daniel
}

\begin{abstract}
Objective-To evaluate olfactory function in Parkinson's disease.

Methods-A standardised odour identification test was used, together with an evoked potential assessment with hydrogen sulphide. In addition, histological analysis was performed on the olfactory bulbs of cadavers who died from Parkinson's disease.

Results-Over $70 \%$ of patients studied (71 of 96) were outside the $95 \%$ limit of normal on the identification test in an age matched sample and there was an unusual pattern of selective loss to certain odours, not hitherto described. The evoked potentials were significantly delayed but of comparable amplitude to a control matched population. Of the 73 patients studied only 37 had a technically satisfactory record containing a clear response to both gases and of these, 12 were delayed. For $\mathrm{H}_{2} \mathrm{~S}$ there was more delay on stimulating the right nostril than the left. Some patients with normal smell identification test scores had delayed evoked potentials. In the pathological examination of olfactory bulbs from eight brains, changes characteristic of Parkinson's disease (Lewy bodies) were seen in every olfactory bulb, particularly in the anterior olfactory nucleus, and were sufficiently distinct to allow a presumptive diagnosis of Parkinson's disease.

Conclusions-Olfactory damage in Parkinson's disease is consistent and severe and may provide an important clue to the aetiology of the disease.
\end{abstract}

Department of Clinical Neurology, Ipswich IP4 5PD, UK

C H Hawkes

B C Shephard

Institute of Neurology, Queen Square, London WC1N 3BG, UK C H Hawkes

Department of Neuropathology, Parkinson's Disease Society Brain Bank, Institute of Neurology, 1 Wakefield Street, London WC1N 1PJ, UK S E Daniel

Correspondence to: Dr C H Hawkes, 22 Henley Rd, Ipswich IP1 3SL, UK. Received 28 May 1996 and in revised form 21 October 1996 Accepted 6 November 1996

$(\mathcal{F}$ Neurol Neurosurg Psychiatry 1997;62:436-446)

Keywords: olfactory evoked potentials; smell identification; Parkinson's disease

There is now good evidence from a wide variety of quantitative psychophysical tests that the ability to smell is substantially affected in Parkinson's disease. For example, Doty and coworkers showed significantly impaired olfaction relative to matched controls in a group of 81 patients with Parkinson's disease. ${ }^{1}$ All had normal cognitive function on formal tests and were assessed by smell identification and odour detection threshold tests. To date, olfactory evoked potential (OEP) techniques, which are not influenced by odour naming or recall ability, have not been systematically applied to patients with Parkinson's disease. Such techniques were pioneered by Kobal and Plattig $^{2}$ and adopted by us. ${ }^{3}$

The basal ganglia have been the subject of intense pathological study in Parkinson's disease, but the rhinencephalon has not been investigated systematically. Chui $e^{t} a^{4}$ examined four patients with Parkinson's disease with dementia and in one brain found an Alzheimer type change in the amygdala, adjacent anterior temporal cortex, and CA2 sector of the hippocampus. The hippocampus was normal in the remaining three cases. It is uncertain whether all the central olfactory areas were examined. Furthermore, the cases were complicated by the presence of dementia.

We have undertaken a multidisciplinary study of olfactory identification, olfactory evoked potential, and pathological examination of the olfactory bulb in Parkinson's disease.

\section{Methods}

After local ethics committee approval and informed consent of patients and controls we undertook the procedures described below.

\section{SMELL IDENTIFICATION TEST}

These measurements were carried out using the University of Pennsylvania smell identification test (UPSIT). ${ }^{5}$ This test uses strips of paper impregnated with microencapsulated odours which are released on scratching the strip with a pencil. There are 40 different odours and a forced choice is made from four possible answers.

\section{Controls}

Normative UPSIT data are available for Americans but because some odours are unfamiliar to British subjects we obtained our own normal values for 96 controls derived from healthy members of hospital and British Telecom staff. Before testing, all patients were asked to estimate their sense of smell on a simple six point scale (very good; good; average; below average; poor; very poor). The nose was checked for patency and a questionnaire was administered to all subjects to probe for history of nasal disease, head injury, use or misuse of drugs, and other conditions (for example, endocrine or hepatic disease) which are occasionally associated with hyposmia.

\section{Patients}

Patients were obtained consecutively from neurological inpatients and outpatients. All 
were examined neurologically at least once by one of us $(\mathrm{CHH})$ and were considered to have idiopathic Parkinson's disease although we are well aware of the roughly $25 \%$ fallibility of such classification. ${ }^{6}$ All patients had intact nasal passages on routine bedside examination and scored $27 / 30$ or more on the mini mental test. If questionnaire analysis suggested nasal disease or any other condition that might impair olfaction (for example, diabetes, severe head trauma, alcoholism) they were excluded. Despite these precautions we are aware that nasal disease may still be present even in apparently healthy people. ${ }^{7}$ Nearly all the patients with Parkinson's disease were receiving levodopa and selegiline but these probably do not affect the ability to smell. ${ }^{89}$ We made no specific tests for depression. Six patients were taking long term tricyclic antidepressants in small doses and two were on long term lithium carbonate for affective disorder. Impairment of sense of smell has not been found in patients with depression (Amsterdam et $a l^{10}$ and our own findings). The effect of depression on olfactory evoked potentials is not known but we suspect that it is unimportant as long as the patient is cooperative.

\section{OLFACTORY EVOKED POTENTIALS}

The term olfactory evoked potential is used in this article to refer to both $\mathrm{H}_{2} \mathrm{~S}$ and $\mathrm{CO}_{2}$ responses. $\mathrm{CO}_{2}$ has no odour and is a stimulant of trigeminal nerve endings in the nose.

The olfactory stimulator we used is similar in construction and design to that described by Kobal $^{11}$ except that our solenoid valves have a slower response time (see below). The stimula- tor overcomes the problem of inadvertent trigeminal stimulation. Anosmic patients tested with this device show no response to primarily olfactory stimulants such as $\mathrm{H}_{2} \mathrm{~S}$ (Kobel and Hummel $^{12}$ and our own findings). Olfactory stimuli are embedded in an odourless bacteriologically pure carrier gas. This is achieved by passing compressed air through a series of five filters. The gas flows at $140 \mathrm{ml} / \mathrm{s}$ and is heated and humidified to match the nasal environment. The principle of stimulus generation is to have two identical gas flows - only one of which contains the odorous substance. Either of the flows can be directed to the nose (fig 1). The air stream is delivered to the nose by means of a teflon tube with a nozzle (internal diameter $4 \mathrm{~mm}$ ) inserted about $1 \mathrm{~cm}$ into one nostril. Between stimuli, only clean air enters the nasal cavity and the air stream containing the odour is vented outside the recording room. Stimulation is carried out by switching the two flows for a preset time using two valves (Festo Ltd) with a fast response time. This eliminates detectable pressure change at the nose and therefore avoids trigeminal activity due to pressure changes. The duration of stimulus containing the test gas is set to $200 \mathrm{~ms}$ in all cases. The characteristics of the pulse have been ascertained by a low flow meter (Si-Plan UK Ltd). The rise time measured at the end of the nasal tubing is approximately $34 \mathrm{~ms}$. This is a composite figure derived from the switching periods of the valves (approximately $10 \mathrm{~ms}$ ); travel along the insulated tubing from the nose to the intranasal cannula (approximately $20 \mathrm{~ms}$ ); and response time of the flow meter itself of $4 \mathrm{~ms}$. The last figure when subtracted from $34 \mathrm{~ms}$ gives a true rise time of around

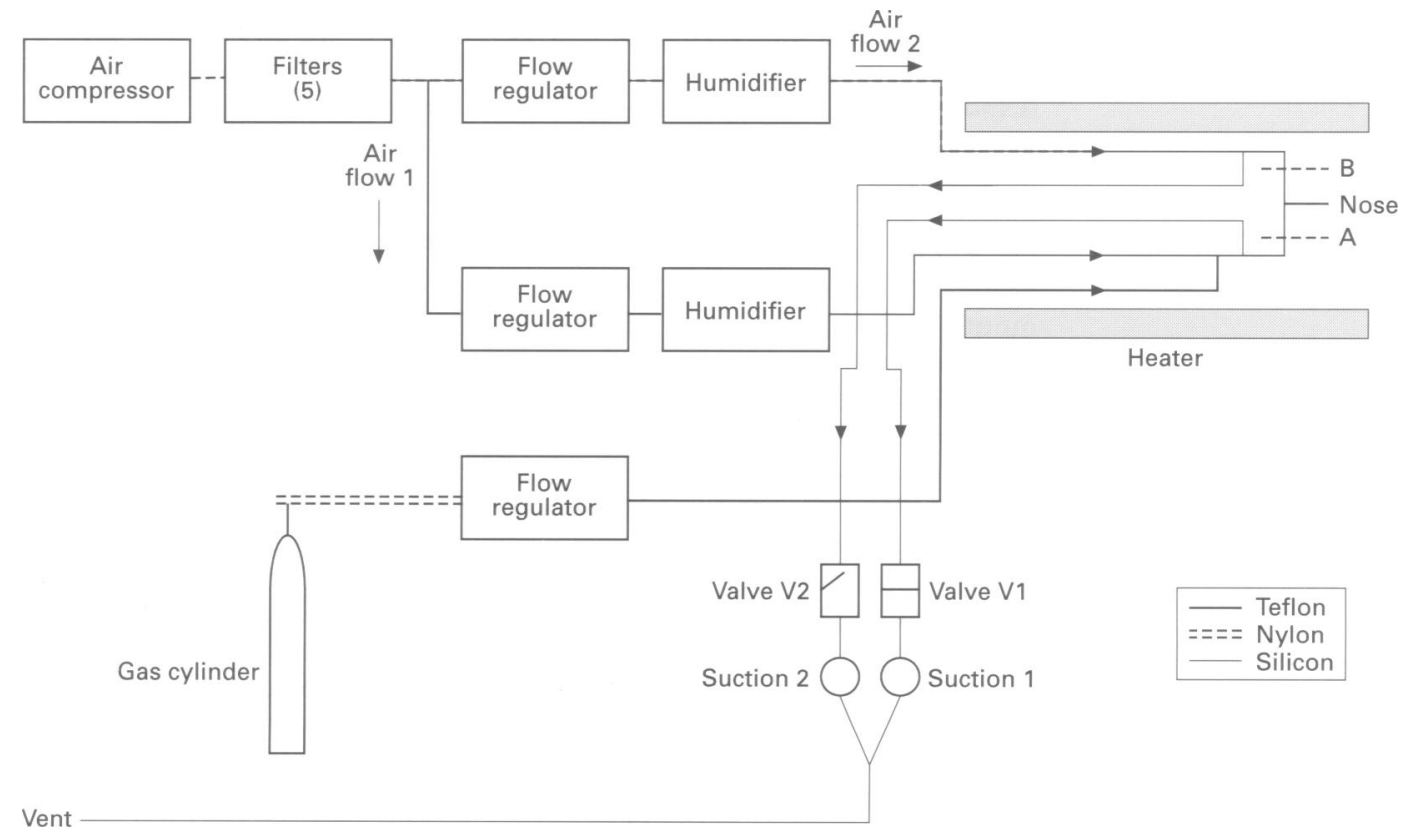

Figure 1 Principle of olfactory stimulation. Here the olfactometer is in stimulus mode. Valve V2 is open and V1 is closed. Pure air flow (2) is diverted by suction 2 and the $\mathrm{H}_{2}$ S/air mixture is delivered to the nose. During the interstimulus interval $V 1$ is open while V2 is closed; the $H_{2}$ Slair mixture is diverted, and only airfow 2 reaches the nose. Before use the apparatus is calibrated so that no $\mathrm{H}_{2} \mathrm{~S}$ enters the nose during the interstimulus period. To ensure that all airflow 2 is removed by suction 2 when the olfactometer is in stimulus mode, the tubing is temporarily blocked at $B$ and suction 2 is adjusted until the flow at the nose is zero. In interstimulus mode V2 is closed and V1 open; flow is blocked at $A$ and suction 1 is adjusted so that flow at the nose is zero. 
Figure 2 (A) $\mathrm{CO}_{2}$ evoked responses in four healthy subjects. Ages and sex are given in the right margin. Traces were derived from $A 1-C Z$ in response to a $200 \mathrm{mS}$ pulse of $50 \% \mathrm{CO}$. Filters were set at $1-50 \mathrm{~Hz}$. Squares represent $12 \cdot 5 \mu \mathrm{V}$ on vertical axis and $200 \mathrm{mS}$ on horizontal axis. (B) $\mathrm{H}_{2} \mathrm{~S}$ evoked responses in four healthy subjects. Parameters as for $\mathrm{CO}_{2}$ except that responses were derived from $A 1-P Z$ and amplitude on the vertical axis is $6.25 \mu \mathrm{V}$. The 200 $m S$ pulse contained $\mathrm{H}_{2} \mathrm{~S}$ at a concentration of $20 \mathrm{ppm}$.

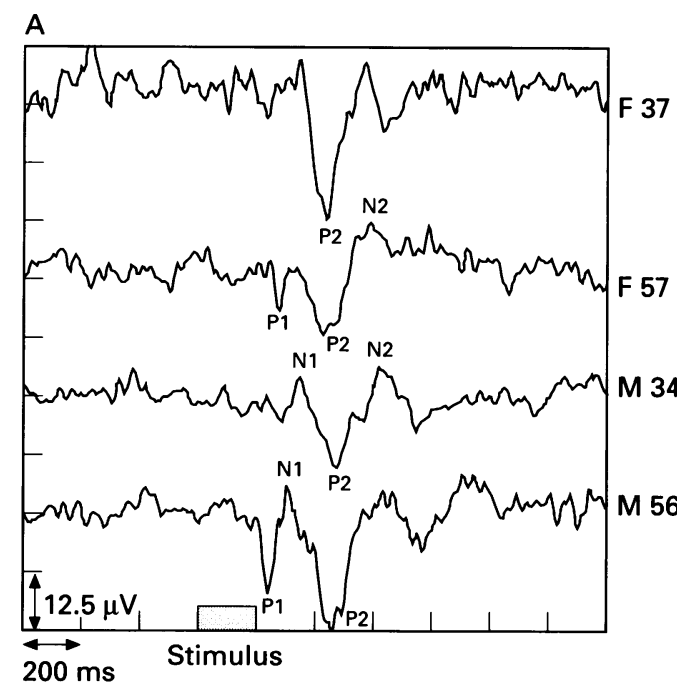

B

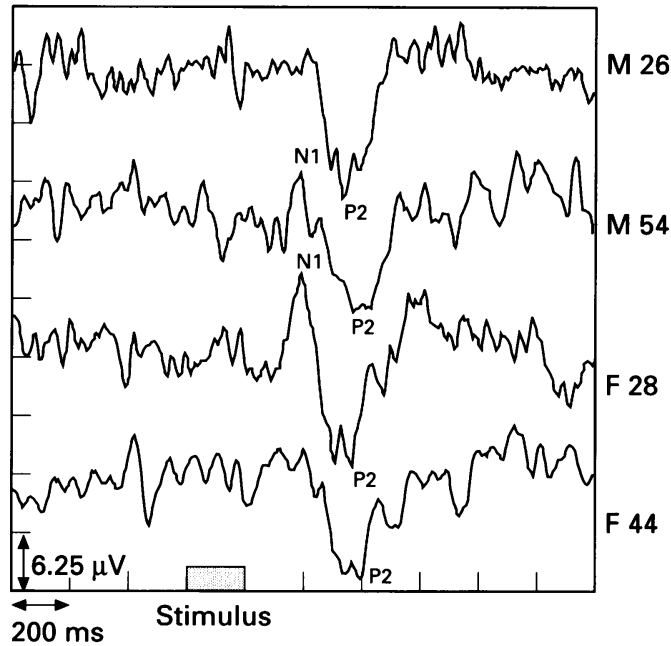

$30 \mathrm{~ms}$. Pressure change on switching the gas streams is small and verified by the fact that no evoked potential has been detected by us in response to a pure air pulse. Objective measurement of the transient pressure change with the flow meter above is difficult because of the rapidity of change at onset and offset of the pulse, but approximates to a difference of flow rate of $1 \mathrm{l} / \mathrm{min}$. Subjects breathe through the mouth to avoid variation in stimulus concentration through nasal breathing. Breathing is monitored by a thermistor taped close to the mouth so that variation of intranasal gas concentration due to inadvertent nasal breathing can be avoided and such potentials rejected. The olfactory stimulant in the present study is $\mathrm{H}_{2} \mathrm{~S}$ ( $20 \mathrm{ppm}$ by volume). Although its odour is somewhat unpleasant, it is a primary olfactory agent which does not elicit a trigeminal response in anosmic patients ${ }^{13}$ The threshold limit volume is $10 \mathrm{ppm}$ for continuous exposure in the workplace. As we use 20 ppm for 11 stimuli (10 averages) of $200 \mathrm{~ms}$ duration any irritant effects are most unlikely. Furthermore, all unwanted gases are removed from the recording environment by use of a powerful extractor fan. This concentration is higher than that used routinely by Kobal ${ }^{11}$ (2ppm). Carbon dioxide ( $50 \%$ by volume) is used in an identical manner. This gas, which is odourless and slightly painful, allows strong nasal trigeminal stimulation and provides an evoked potential of shorter latency than $\mathrm{H}_{2} \mathrm{~S}$. For $\mathrm{H}_{2} \mathrm{~S}$ an interstimulus interval (ISI) of 60 seconds is used and for $\mathrm{CO}_{2} 40$ seconds. ${ }^{13}$

The cerebral response is recorded at $\mathrm{CZ}$ and $\mathrm{PZ}$ using the standard 10/20 system referenced to A1. The electro-oculogram is simultaneously averaged and any trial contaminated by eye blinks or other muscle artefacts is discarded. Typically a $2048 \mathrm{~ms}$ epoch is used of which 600 $\mathrm{ms}$ is presignal. Filters are set at $1-50 \mathrm{~Hz}$ and amplification at $10 \mu \mathrm{V} / \mathrm{cm}$. Ten to 16 artefact free signals are averaged on a Nihon-Kohden Neuropak-4 machine, which uses 256 data points per channel. The averaged trace is smoothed by one pass of a nine point filter (equivalent to a low pass filter of $27 \cdot 5 \mathrm{~Hz}$ ). Latency measurements are unaffected by this filter setting but there is slight reduction of amplitude. Latencies are measured from the start of the trigger pulse. The stimulus reaches the nostril approximately $10 \mathrm{~ms}$ afterwards; because this interval is short by comparison with the initial N1 response, it is ignored in latency calculations. A simple visual tracking task is performed to maintain a constant state of alertness. Subjects use a joystick to centre a small square in a slowly moving large square displayed on a 14 inch computer monitor at a distance of about 1 metre. Headphones delivering white noise are worn to mask out auditory clues from switching devices. Figure 2 shows a sample of normal $\mathrm{CO}_{2}$ and $\mathrm{H}_{2} \mathrm{~S}$ averaged responses derived from four healthy subjects. The $\mathrm{P} 1$ and $\mathrm{N} 2$ responses are often undetectable and N1 is sometimes indistinct even in healthy people. Latencies are measured to the first negative peak (N1) and second positive trough (P2). If the N1 response is not clearly visible, its position is estimated from the point of downward (positive) deviation from baseline of the P2 response. Stimuli are presented unilaterally; the most patent nostril is usually selected for testing but if results are obtained from both nostrils then the mean latency and amplitude is used unless specified otherwise. Amplitude is measured from the peak of N1 to the trough of $\mathrm{P} 2$.

\section{Controls}

We used 47 controls (aged 17-74; 18 men, 29 women; mean age 45.6 years) who had responses to both gases derived from the 96 making up the UPSIT group. Only 71 of 96 agreed to be tested and of these 24 had unreliable tracings. The main reason was that subjects found that stimulation with $50 \% \mathrm{CO}_{2}$ was too uncomfortable although they could tolerate lower concentrations and showed a normal evoked response.

\section{Patients}

A total of 74 patients with Parkinson's disease were examined who were also extracted from the UPSIT group. For statistical analysis we used only those patients ( 37 altogether) with a clear response to both gases. There were 19 men and 18 women aged 27-77 years, mean age 62 years. 
Figure 3 Logit transformation of UPSIT score plotted against age. $\bigcirc$ Actual scores for controls; $\boldsymbol{\Delta}$ actual scores for patients.

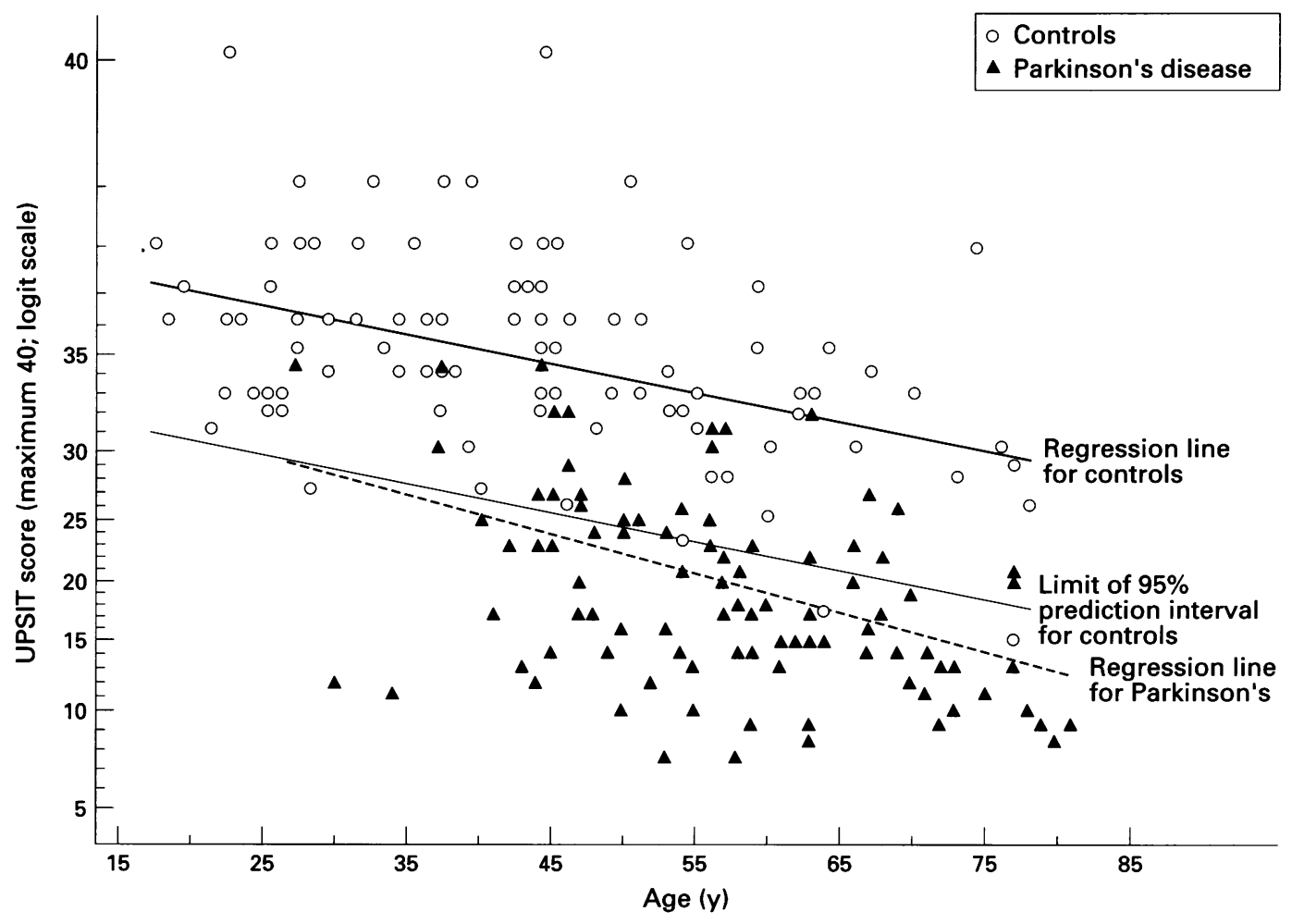

OLFACTORY BULB PATHOLOGY

Olfactory bulbs and tracts were removed from formalin fixed half brains of eight patients with a clinical and pathological diagnosis of Parkinson's disease. All were taken from tissue in the United Kingdom Parkinson's Disease Brain Bank. None had olfactory testing by us. There were four male and four female patients aged 67-76 (mean $72 \cdot 25$ years) and three male and five female controls aged 58-80 years (mean age 74.13 years). Tissue was processed in paraffin wax and serial horizontal sections of the entire nerve were cut at $7 \mu$. The first and every 10th section were stained with haematoxylin and eosin and the immediately adjacent sections were stained with antisera for ubiquitin (Dako, polyclonal 1:150) and modified Bielschowsky silver impregnation. Sections were examined "blind" to clinical information. Cases were classified as "probable Parkinson's disease" or "non-Parkinson's disease" on the basis of whether Lewy bodies were seen, and results subsequently compared with the diagnosis after full neuropathological examination.

\section{Results}

SMELL IDENTIFICATION TESTS (UPSIT)

Altogether we tested 96 patients with Parkinson's disease (aged 27-81 years, 49 men, 47 women; mean age 57.0 years) and 96 controls (aged 18-78 years; 39 men, 57 women; mean age 41.7 years). For UPSIT scores the proportion of correct answers (p) was first transformed using the logit transformation, $\log (p /(1-p))$, because $p$ was skewed towards 1 , especially for the controls. The UPSIT scores for patients with Parkinson's disease were significantly lower than those for controls (P<0.0001). Only 26\% (25 of 96) of the patients with Parkinson's disease had a score within the level expected for $95 \%$ of our healthy controls (fig 3). There was no evidence of qua-

We examined whether any of the 40 different odours in the UPSIT gave greater difficulty in identification for patients compared with controls. From 96 patients and 96 controls we matched 70 controls and 70 patients on the basis of sex and age \pm 3 years. There were 35 of each sex. The mean age of controls was 54.7 years and of patients $\mathbf{5 5 . 4}$ years. We calculated the percentage of correct scores for each odour determined the difference between the two percentages (fig 4 ). The vertical line is set at $31 \%$, which is the average of all 40 differences in proportions. The confidence intervals are derived from McNemar's test for differences between two paired proportions with the confidence level adjusted to allow for the fact that 40 statistical tests were being carried out. If any of these corrected confidence intervals wholly exceeded the average difference of $31 \%$, the difference between control and patient responses on this natural (random) component to component variation, which would be expected. The most significant results are shown at the top, the least significant at the bottom.

Figure 5 is a plot of sensitivity against specificity for all 40 odours in the UPSIT. A combination of pizza and wintergreen was the best discriminator, with a sensitivity of $90 \%$ and specificity of $86 \%$. Inclusion of a third odour did not improve the separation of controls from patients. Because subjects made a forced choice of one answer from four possibilities, $25 \%$ of answers will be correct by chance alone. Hence the sensitivity value $(76 \%)$ for pizza (percentage of patients scoring incorrectly), in the presence dratic effects. in the control group and the patient group and particular component would be in excess of the 
Figure 4 Results of UPSIT test to all 40 odours compared with controls. The differences are shown, with associated 95\% confidence intervals, between the percentages of controls and patients with correct answers for each of the 40 individual components of the UPSIT. The vertical line is set at $31 \%$, which is the average of all 40 differences in proportions. The most significant results are shown at the top, the least significant at the bottom. See text for fuller explanation of method.

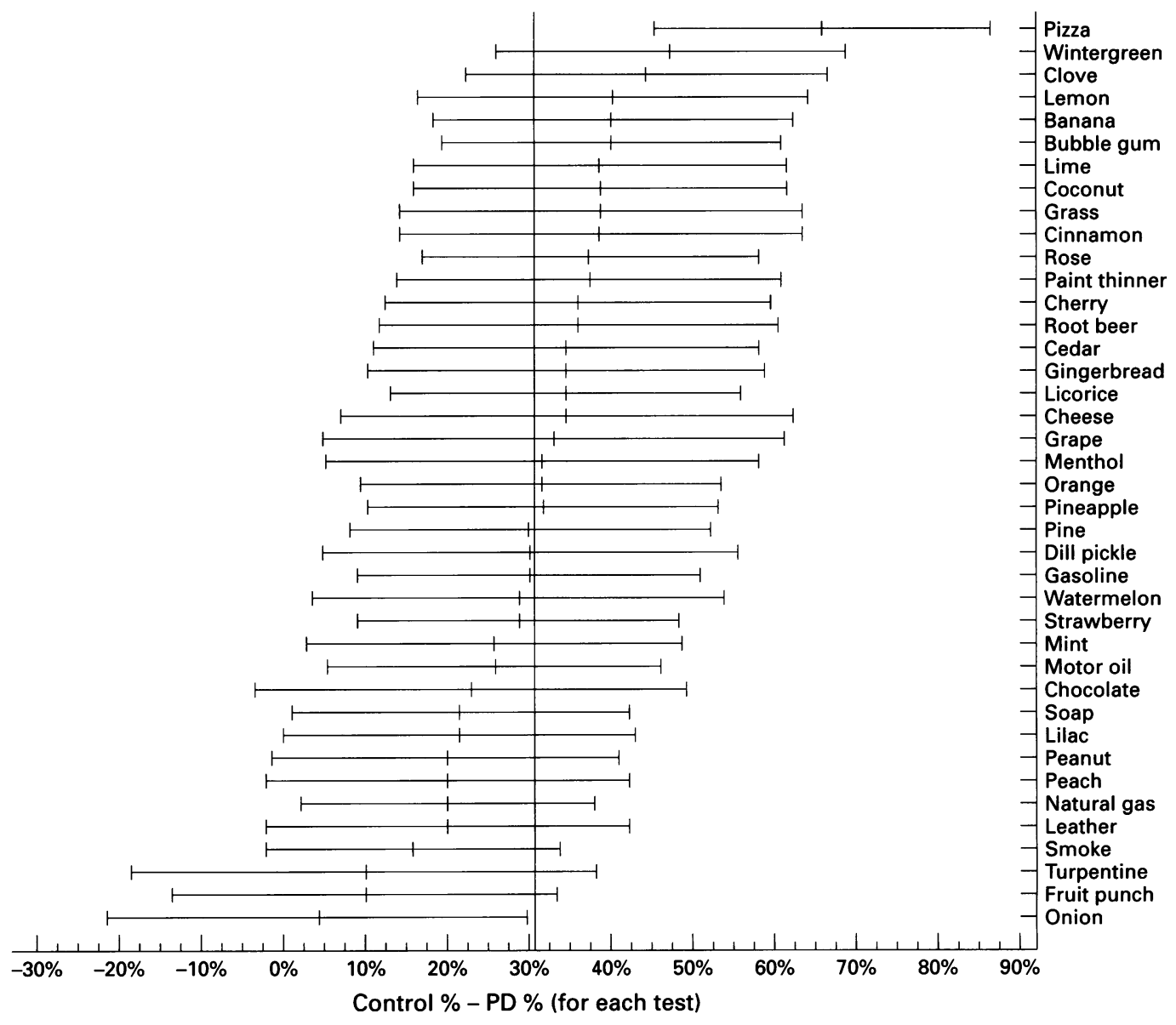

of $90 \%$ specificity (percentage of controls scoring correctly) for this odour indicates anosmia to pizza for patients with Parkinson's disease.

There was no correlation between duration of disease and UPSIT score $(r=0.074)$. Patients were asked for a subjective estimate of their sense of smell and this correlated broadly with their UPSIT score $(r=0.47, \mathrm{P}<0.001)$.

EVOKED POTENTIALS

A response was considered absent if no visible

Figure 5 Plot of sensitivity (percentages of cases answering incorrectly) against specificity (percentage of controls answering correctly) for each of the 40 test odours in UPSIT. The specificity axis is reversed to give a graph similar to the receiver operating characteristic curve. $A$ "perfect" discriminatory. test will have a sensitivity and specificity of $100 \%$ and will be located in the top left corner of the graph. $A$ poor test will be located in the bottom right corner. Discriminant analysis suggests that pizza and wintergreen in combination provide the best discrimination with a sensitivity of $90 \%$ and specificity of $86 \%$.

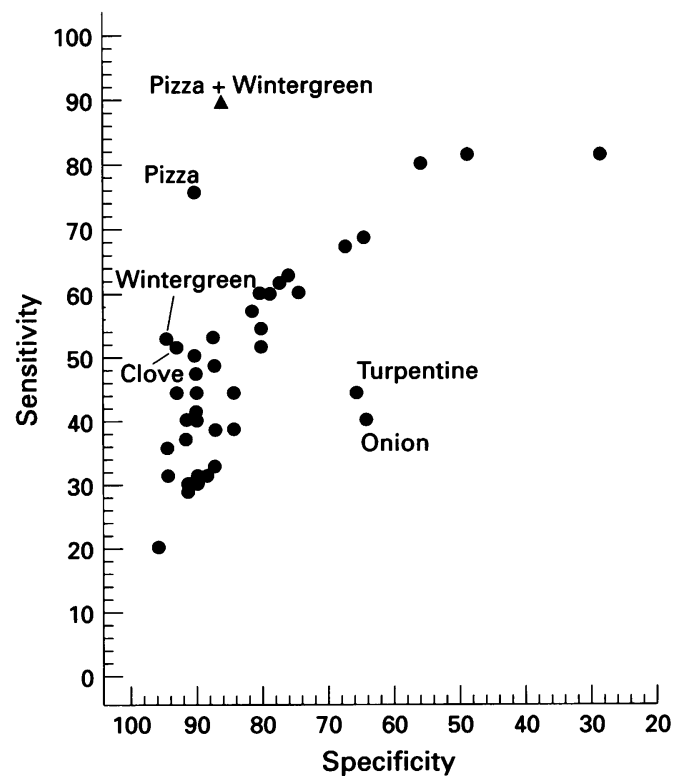

waveform was detectable in an artefact free recording. Forty seven controls were used for both gases as described in the methods section.

Carbon dioxide (50\% concentration volume/air in all cases)

Sixty six patients with Parkinson's disease were tested initially but six were rejected: five had unclear recordings and one was absent. This left 60 patients and there were only 37 who responded to both $\mathrm{CO}_{2}$ and $\mathrm{H}_{2} \mathrm{~S}$. Figure $6 \mathrm{~A}$ shows the olfactory evoked response at $\mathrm{CZ}$ due to stimulation by $\mathrm{CO}_{2}$ for a selection of patients with Parkinson's disease.

Hydrogen sulphide (20 ppm in all cases)

There were 73 patients with Parkinson's disease tested in whom 21 responses were absent, and six unclear. This left 46 results with 37 patients who had clear responses to both $\mathrm{CO}_{2}$ and $\mathrm{H}_{2} \mathrm{~S}$. Figure $6 \mathrm{~B}$ shows the olfactory evoked response at $\mathrm{PZ}$ due to stimulation by $\mathrm{H}_{2} \mathrm{~S}$ for a selection of patients with Parkinson's disease.

The N1 and P2 distributions were normal but the amplitude distribution was skewed. It was decided to use $\log _{e}$ transformation on all three variables as this not only normalised the amplitude distribution but stabilised the variances between the two groups for N1 and P2. For each transformed variable, regression analysis was carried out adjusting for age to see if any significance could be attributed to differences due to diagnosis - that is, whether Parkinson's disease or control. For $\mathrm{H}_{2} \mathrm{~S}$ (but not $\mathrm{CO}_{2}$ ) a highly significant difference existed 
Figure 6 (A) $\mathrm{CO}_{2}$ evoked responses in four patients with Parkinson's disease; ages and sexes are given in the right margin. Traces were derived from $A 1-C Z$ in response to a $200 \mathrm{mS}$ pulse of $50 \%$ $\mathrm{CO}_{2}$. Filters were set at 1-50 Hz. Squares represent $12.5 \mu \mathrm{V}$ on vertical axis and $200 \mathrm{mS}$ on horizontal axis. (B) $\mathrm{H}_{2} \mathrm{~S}$ evoked responses in four patients with

Parkinson's disease.

Parameters as for $\mathrm{CO}_{2}$ except that responses were derived from A1-PZ and amplitude on the vertical axis was $6 \cdot 25 \mu \mathrm{V}$. The $200 \mathrm{mS}$ pulse contained $\mathrm{H}_{2} \mathrm{~S}$ at a concentration of $20 \mathrm{ppm}$.

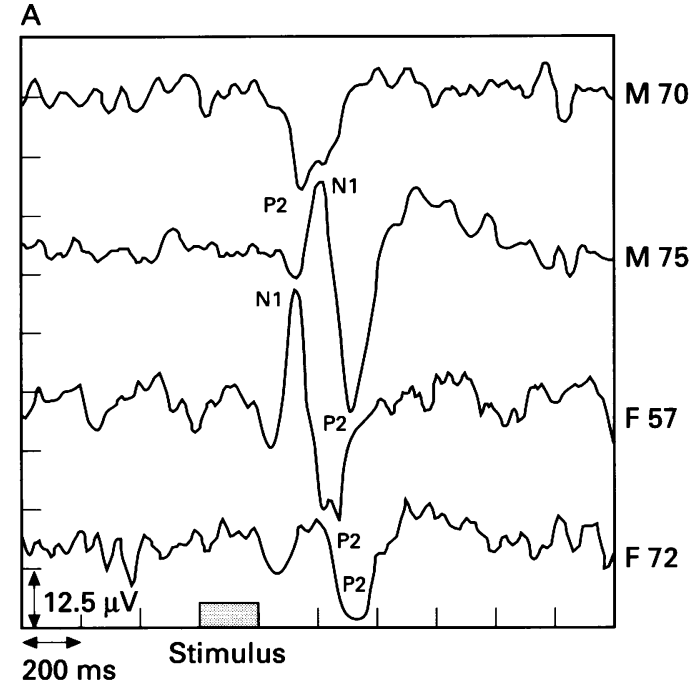

B

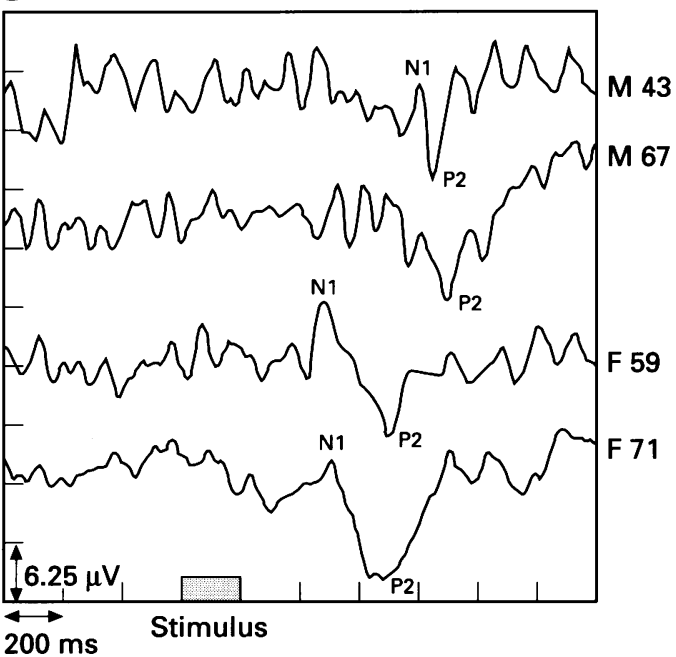

between diagnostic groups for P2 latency but not N1 latency or N1-P2 amplitude (table 1).

We were able to test 10 patients with normal UPSIT scores using olfactory evoked potentials. These patients therefore scored within the $95 \%$ age adjusted limits of our healthy control group. One of the 10 patients had absent $\mathrm{H}_{2} \mathrm{~S}$ responses and three had significantly prolonged latencies after stimulation of one or both nostrils with $\mathrm{H}_{2} \mathrm{~S}$. All had intact $\mathrm{CO}_{2}$ responses.

There were 13 patients with Parkinson's disease and nine unmatched controls who had all shown clear responses from both nostrils. The nostril first stimulated was randomly assigned to either side (that is, right then left or left then right). Regression analyses were undertaken separately for N1 and P2 latency and N1-P2 amplitude to see if the slopes of the latency and amplitude against age differed significantly between patients and controls. In no instance was there a difference in slopes between patients and controls. The difference between these regression lines was tested for any disparity in the magnitude of latencies or amplitudes between patients and controls after allowing for age (table 2). Table 2 shows that $\mathrm{H}_{2} \mathrm{~S}$ signals for stimulation of the right nostril in the Parkinson's disease group are significantly
Table 1 Differences in regression lines for $\mathrm{CO}_{2}$ and $\mathrm{H}_{2} \mathrm{~S}$ latency and amplitude between patients with Parkinson's disease (PD) and controls

\begin{tabular}{lll}
\hline & $\begin{array}{l}\text { Difference } \\
\text { (PD-control) }\end{array}$ & P value \\
\hline $\mathrm{CO}_{2}:$ & & \\
$\mathrm{N} 1$ & $9 \mathrm{~ms}$ & 0.26 \\
$\mathrm{P} 2$ & $32 \mathrm{~ms}$ & 0.88 \\
Amp & $-7.6 \mu \mathrm{V}$ & 0.07 \\
$\mathrm{H}_{2} \mathrm{~S}:$ & & \\
$\mathrm{N} 1$ & $64 \mathrm{~ms}$ & 0.96 \\
$\mathrm{P} 2$ & $100 \mathrm{~ms}$ & $0.01^{\star}$ \\
Amp & $1.7 \mu \mathrm{V}$ & 0.5 \\
\hline
\end{tabular}

Results were obtained by regressing latency/amplitude on age for each year. Amp = amplitude. ^Significant.

Table 2 Parkinson's disease (PD) - control differences for $\mathrm{H}_{2} \mathrm{~S}$ between left and right nostril regression lines after allowing for age

\begin{tabular}{lll}
\hline & $\begin{array}{l}\text { Difference } \\
\text { (PD-control) }\end{array}$ & P value \\
\hline Left: & & \\
N1 & $30 \mathrm{~ms}$ & 0.53 \\
P2 & $11 \mathrm{~ms}$ & 0.79 \\
Amp & $-1.6 \mu \mathrm{V}$ & 0.34 \\
Right: & & \\
N1 & $140 \mathrm{~ms}$ & $0.001^{\star}$ \\
P2 & $124 \mathrm{~ms}$ & $0.0001^{\star}$ \\
Amp & $2.3 \mu \mathrm{V}$ & 0.91 \\
\hline
\end{tabular}

Data are for both nostrils from 13 patients with Parkinson's disease (mean age 57 years) and nine controls (mean age 51 years). Amp = amplitude.

51 years). Amp
$\star$ Significant.

Table 3 Differences between left and right nostril N1 and $P 2$ latencies and N1-P2 amplitude $\left(\mathrm{H}_{2} \mathrm{~S}\right)$ for nine controls and 13 patients

\begin{tabular}{lll}
\hline & $\begin{array}{l}\text { Difference } \\
\text { (eft-right) }\end{array}$ & $\begin{array}{l}\text { P value } \\
\text { (paired t test) }\end{array}$ \\
\hline PD: & & \\
N1 & $-54 \mathrm{~ms}$ & $0 \cdot 21$ \\
P2 & $-38 \mathrm{~ms}$ & $0 \cdot 28$ \\
Amp & $0.4 \mu \mathrm{V}$ & $0 \cdot 79$ \\
Control: & & \\
N1 & $58 \mathrm{~ms}$ & $0 \cdot 19$ \\
P2 & $82 \mathrm{~ms}$ & $0 \cdot 04^{\star}$ \\
Amp & $2 \cdot 3 \mu \mathrm{V}$ & $0 \cdot 27$ \\
\hline
\end{tabular}

Mean ages of patients with Parkinson's disease was 57 years and that of the controls was 56 years. Amp = amplitude. ^Significant.

delayed in comparison with the controls. The differences in latency and amplitude between left and right nostrils were tested using a paired $t$ test separately for patients and controls. Within the Parkinson's disease or control groups there were no significant differences except for slight prolongation of P2 latency in controls after left nostril stimulation compared with the right (table 3 ).

For $\mathrm{CO}_{2}$ and $\mathrm{H}_{2} \mathrm{~S}$ in controls there was significant correlation of UPSIT score with N1P2 amplitude ( $\mathrm{P}<0.006, r=0.37$ for $\mathrm{CO}_{2}$; $\mathrm{P}<0.001, r=0.44$ for $\mathrm{H}_{2} \mathrm{~S}$ ) and for latency $\left(\mathrm{P}<0.05, r=-0.29\right.$ for $\mathrm{CO}_{2}$ to $\mathrm{P} 2$ only; $\mathrm{P}<0.05 ; r=-0.25$ for $\mathrm{H}_{2} \mathrm{~S}$ to $\mathrm{N} 1$ only). For $\mathrm{CO}_{2}$ in patients there was no correlation of UPSIT score with latency or amplitude measurements. For $\mathrm{H}_{2} \mathrm{~S}$ in patients there was correlation of $\mathrm{N} 1$ and $\mathrm{P} 2$ latency $(\mathrm{P}<0.001$ $r=-0.54 ; \mathrm{P}<0.001, \quad r=-0.62$ respectively) but not N1-P2 amplitude. (Spearman's rank correlation coefficient for all analyses).

PATHOLOGICAL STUDY

By examining the olfactory bulb and tract all 
Figure 7 (a) The anterior olfactory nucleus in Parkinson's disease. Intraneuronal Lewy bodies (some arrowed) are easily identified using ubiquitin immunocytochemistry. Occasional neurites (arrowheads) are also immunoreactive. Avidinbiotin-peroxidasel haematoxylin, bar $=$ $50 \mu$. (b) Nerve cells of the anterior olfactory nucleus contain Lewy bodies (arrows) which are homogeneous hyaline inclusions resembling those found in the cerebral cortex. Haematoxylineosin, bar $=25 \mu$. (c) Occasional Lewy bodies in the olfactory bulb show a classic "cored" appearance.

Haematoxylin-eosin, bar $=10 \mu$.
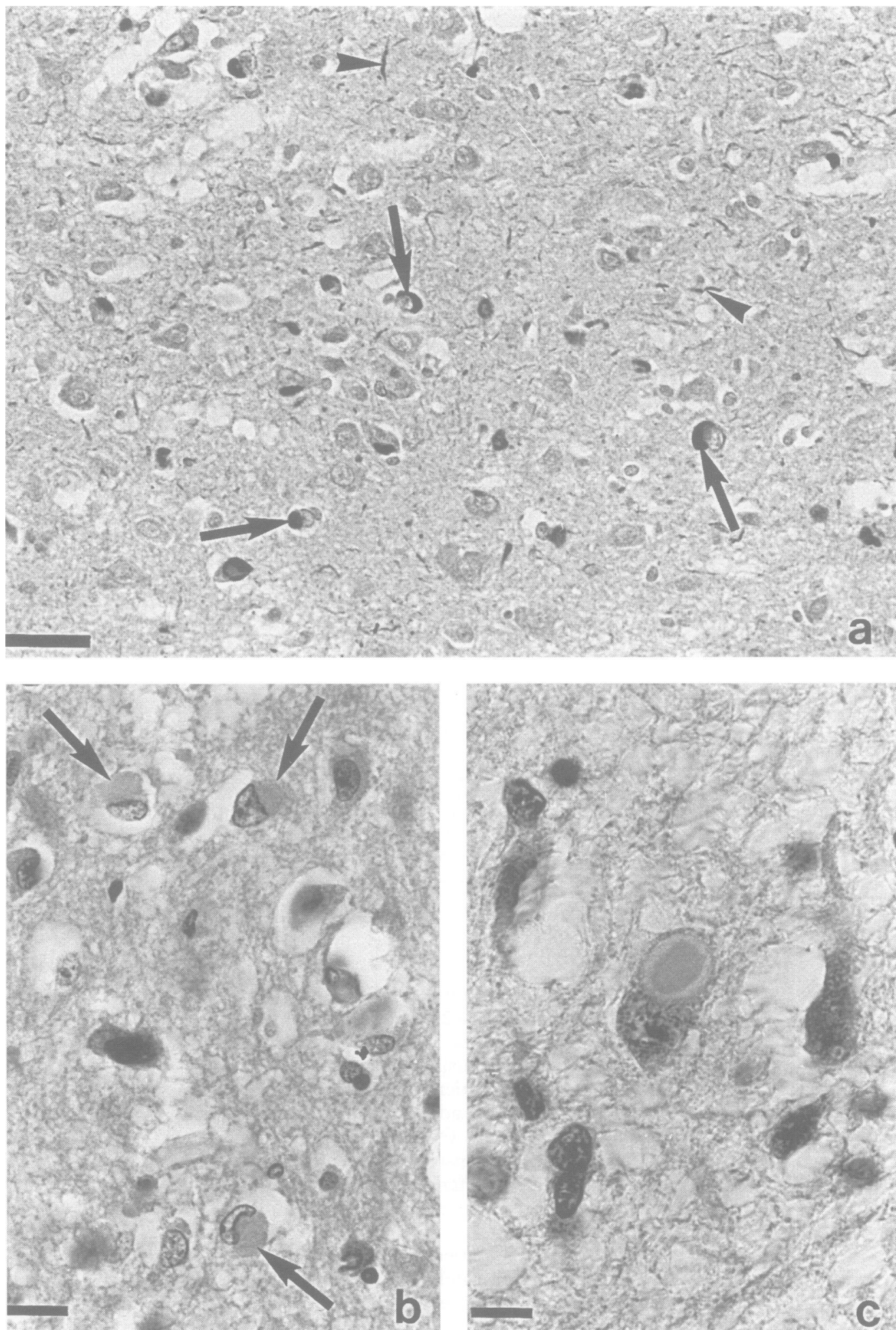

eight cases were correctly diagnosed "probable Parkinson's disease."

There were no Lewy bodies in any control sample. Lewy bodies were best identified using ubiquitin immunocytochemistry (fig 7a) and were most numerous in the anterior olfactory nucleus; they were also found occasionally in mitral cells. The morphology of Lewy bodies at this site resembled their cortical counterparts (fig 7b) and inclusions showing a classic trilaminar structure were rare (fig 7c). In two cases Lewy bodies were plentiful and associated with distended ubiquitin immunoreactive neurites. In one case there were also many neurofibrillary tangles and a few senile plaques involving the anterior olfactory nucleus in a patient who had Alzheimer's disease. Full histological examination of the brains confirmed the diagnosis of Parkinson's disease. In the two brains with numerous olfactory Lewy bodies and swollen ubiquitin immunoreactive neurites, cortical Lewy bodies notably in the anterior cingulate gyrus and parahippocampus, were also plentiful. Many 
distended neurites in the CA2 region of the hippocampus said to be characteristic for diffuse Lewy body disease were also identified. Age related degenerative changes with numerous corpora amylacea were identified in al bulbs; in one elderly control there were occasional neurofibrillary tangles in the anterior olfactory neurons.

\section{Discussion}

Our data have substantiated earlier reports of abnormalities in smell identification in Parkinson's disease and additionally show abnormal olfactory evoked potentials and specific pathological changes in the olfactory bulb.

\section{SMELL IDENTIFICATION}

The UPSIT data for Parkinson's disease are similar to those described by Doty and colleagues ${ }^{1}$ except that our series is slightly larger and contains more young patients-down to 27 years. These authors suggested that olfactory dysfunction was unrelated to odour type, did not depend on disease duration, and did not correlate with motor function, tremor, or cognition, as was also found by others. ${ }^{9}$ Doty et $a l^{8}$ also showed that the deficit was of the same magnitude in both nostrils, and was not influenced by antiParkinsonian medication. As reported by Doty et $a l^{1}$ we also found no correlation of UPSIT with duration of disease. Whereas there was clearly a background depression of olfactory identification, superimposed on this was a degree of selective odour deficit-something that was not documented by Doty's group. Odours that were most readily misidentified were lemon, pizza, wintergreen, rose, and clove. Pizza was the best single discriminant odour with pizza and wintergreen in combination better still. Thus a subject could be suspected of having Parkinson's disease if both pizza and wintergreen were inaccurately identified and would probably not have the disease if both of these odours were positively smelt correctly (not by random guessing). Because subjects made a forced choice of one from four possibilities, $25 \%$ will be correct by chance alone. Hence a sensitivity value of $76 \%$ for pizza in the presence of $90 \%$ specificity indicates anosmia to pizza for patients with Parkinson's disease. It is difficult to explain why this should be. Controls and patients were matched for age and sex as these variables influence the UPSIT score in Parkinson's disease. ${ }^{14} \mathrm{We}$ did not have sufficient numbers to match for other factors which might influence the result, such as intelligence or social class; nor were we able to allow for variation in odour intensity due to errors in manufacture. Although lemon, wintergreen, and clove have some trigeminal stimulation, pizza (oregano smell) and certainly rose are mainly olfactory. Whatever the mechanism, these findings raise the possibility that there may be a congenital or acquired selective hyposmia in Parkinson's disease comparable with androstenone smell blindness which affects $20 \%-47 \%$ of healthy people. ${ }^{15}$ Of particular relevance is a study in which rats were exposed to 44 inhaled vapours for several weeks. ${ }^{16}$ For each odour there was a selective pattern of mitral cell loss in the olfactory bulb which was unrelated to odour concentration. It is thus conceivable that the olfactory damage in Parkinson's disease may be caused by exposure to a neurotoxic vapour which selectively injures part of the olfactory system. Speculatively it should be possible to "work back" from the olfactory bulb pathology and describe the chemical characteristics of a possible neurotoxin.

It was noted ${ }^{1}$ that only $28 \%$ of patients with Parkinson's disease were aware of some olfactory or taste impediment on a simple yes or no rating scale before formal testing. We found that patients had a reasonable idea of their smell sense as judged by a six point rating scale compared with UPSIT score. These two findings are comparable although different techniques of analysis were used. We did not measure motor disability on a rating scale such as Hoehn and $\mathrm{Yahr}$ as it is a relatively crude assessment and earlier findings had implied that there was no correlation between motor function and smell defect. ${ }^{19}$

\section{EVOKED POTENTIALS}

Our main finding has been an absent or delayed $\mathrm{H}_{2} \mathrm{~S}$ evoked response in a few patients with Parkinson's disease. The latency rather than amplitude abnormality is an unexpected finding of possible diagnostic value. The increase in $\mathrm{H}_{2} \mathrm{~S}$ latency was only apparent to P2 not N1. This suggests that the main change is a reduction of N1-P2 gradient causing a broader wave shape. In our earlier study of multiple sclerosis there was significant change in latency. ${ }^{3}$ Because Parkinson's disease is not a demyelinating condition we did not expect to find a latency change and can offer no explanation for this at present. Our patient and control groups are not well matched for age. As there are more elderly patients than controls this might inflate any difference between the two groups, especially in the older age range. However, age was allowed for in the regression analysis. The large number of absent responses (27 of 73 ) was partly due to technical difficulty in obtaining the olfactory evoked potential, which is considerably greater than comparable procedures such as visual, auditory, and somatosensory responses. Apart from the need for repeated checking of the signal it is possible to average 20 signals at most because of the necessarily prolonged interstimulus interval (60 seconds) required. It is not surprising that so many were absent as the patients with Parkinson's disease had a poor sense of smell generally and the few delayed $\mathrm{H}_{2} \mathrm{~S}$ responses in those we could test may be a reflection of a healthier population in the olfactory sense. Sometimes technical difficulties brought the recording session to a premature halt or a problem was experienced with involuntary movement, making it difficult for the patient to keep the tubing in the nose. Even in healthy controls six of $69(7 \%) \mathrm{H}_{2} \mathrm{~S}$ recordings were unsuccessful. For $\mathrm{CO}_{2}$, responses were unobtainable in six of $66(9 \%)$ 
patients and six of $56(9 \%)$ controls. The number of healthy controls used was reduced to 47 as we accepted only those with responses to both gases. All controls who were rejected tolerated $40 \% \quad \mathrm{CO}_{2}$ but they had to be excluded because of intolerance to $50 \% \mathrm{CO}_{2}$. The UPSIT is the superior test with more than $70 \%$ abnormality in Parkinson's disease. This contrasts with 12 of 37 (32\%) delayed responses to $\mathrm{H}_{2} \mathrm{~S}$ in patients. A record which is labelled absent may in fact contain a response which is below the limit of detection imposed by averaging 16 signals. We have used only one odour whereas the UPSIT implements 40 . If three or four different gases were used the sensitivity of olfactory evoked potentials might well increase.

The correlation of UPSIT score with latency and amplitude measurements in controls for $\mathrm{H}_{2} \mathrm{~S}$ is to be expected as identification might well be easier with a more vigorous cerebral signal. This association does not hold good for patients exposed to $\mathrm{H}_{2} \mathrm{~S}$ in whom the correlation is strong with latency but not amplitude.

In one study ${ }^{13}$ eight patients with Parkinson's disease were compared with age matched controls using a simple odour identification test and by measuring the olfactory evoked potential after stimulation with vanillin and $\mathrm{H}_{2} \mathrm{~S}$. The olfactory evoked potentials to $\mathrm{H}_{2} \mathrm{~S}$ and vanillin were of longer latency in the Parkinson's disease group although these were only significant on left nostril stimulation; amplitudes did not differ. Our data confirm this pilot study in that we discovered significant prolongation of latency to $\mathrm{P} 2$ in the Parkinson's disease group but we found increased latency (without amplitude change) compared with controls for $\mathrm{H}_{2} \mathrm{~S}$ when the right nostril was stimulated compared with the left. In keeping with their studies in healthy subjects ${ }^{13}$ we found more delay on right nostril stimulation for $\mathrm{H}_{2} \mathrm{~S}$. It is not clear why there is such a discrepancy but in both instances the numbers studied were small and our results should only be regarded as provisional. Furthermore we necessarily selected those with an $\mathrm{H}_{2} \mathrm{~S}$ response which was not too difficult to elicit. Ideally a right, left, left, right or left, right, right, left nostril stimulation sequence should be used but it is unlikely that patients would tolerate such a lengthy test procedure.

Of particular interest is our finding of abnormal $\mathrm{H}_{2} \mathrm{~S}$ responses in four of 10 patients (one absent, three delayed) with normal UPSIT score. Viewed alone the UPSIT results place $74 \%$ of patients outside the $95 \%$ limit for controls. When this information is combined with olfactory evoked potential data the fraction of olfactory abnormality exceeds $80 \%$. Such frequency is greater than that of tremor, which is usually quoted at $70 \%{ }^{17}$ and nearly equals that of rigidity and akinesia. At least for a hospital (rather than community population) olfactory dysfunction would seem to be as common and presumably as important as the cardinal motor signs of Parkinson's disease.
OLFACTORY BULB PATHOLOGY

The finding of Lewy body damage in the olfactory bulb was first reported briefly by us earlier. ${ }^{18}$ In every instance the Parkinson's disease specimens were readily distinguished from controls. Furthermore in two cases with severe involvement of olfactory bulbs the cerebral cortex was similarly affected and cortical Lewy bodies were numerous. In one case there was coexistent Alzheimer's disease with neurofibrillary tangles and senile plaques present in the neocortex and olfactory bulb-as already documented. ${ }^{19-21}$ In our Parkinson's disease series, Lewy bodies were most readily identified in the anterior olfactory nucleus. Detailed topographical analysis and cell counting will be required to determine whether these neurons are selectively vulnerable or if additional neuronal types-for example, mitral and granule cells - are similarly affected. Our findings suggest that inspection of the olfactory bulb allows preliminary diagnosis of Parkinson's disease. An initial diagnosis of other neurodegenerative diseases may also be made in this way-for example, Alzheimer's disease, Pick's disease (Yoshimura ${ }^{21}$ and personal observations) and multiple system atrophy, ${ }^{18}$ a finding which may be particularly useful before whole brain postmortem studies are undertaken. The importance of these morphological changes to the smell defect in Parkinson's disease and the extent of central olfactory involvement remain to be elucidated.

Our data show that olfaction is discretely impaired in $70 \%-90 \%$ of patients with Parkinson's disease and that damage is present in the initial part of the olfactory pathwaynamely, the bulb. Why should a movement disorder be so consistently associated with hyposmia? The olfactory identification defect in Alzheimer' disease is said to be identical to Parkinson's disease ${ }^{8}$; there is profound disturbance of cognition in Alzheimer's disease but only in a minor proportion of patients with Parkinson's disease. One possibility is that Parkinson's disease and perhaps Alzheimer's disease might be caused by a virus or chemical agent that gains entry to the CNS via the nose. One group ${ }^{22}$ were able to show that HSV1 virus placed intranasally in six week old mice could be detected in the brain stem trigeminal root entry zone and the olfactory bulbs four days later. In some mice, viruses which had entered the olfactory bulb had spread as far as the temporal lobe, hippocampus, and cingulate cortex. Another ${ }^{23}$ showed that horseradish peroxidase applied intranasally was transported to the bulb, anterior olfactory nuclei, and transmitter specific projection neurons from the diagonal band (cholinergic), raphe (serotonergic), and locus coeruleus (noradrenergic). All these zones are known to project widely to non-olfactory areas of the CNS. Because of the ease with which a large macromolecule such as horseradish peroxidase could spread it was reasoned ${ }^{23}$ that environmental contaminants and perhaps drugs of misuse could gain relatively unimpeded access to the entire nervous system. A further possibility is the effect of inhaled solvents such as 
trichloroethylene, which may rekindle activity in latent viruses such as herpes simplex. ${ }^{24}$ Support for the nasal entry theory might be strengthened if there was a correlation between the olfactory and motor deficitseither in terms of severity or duration of symptoms. However, this has not been found. ${ }^{1}$ At present there is no convincing evidence that subjects with anosmia later develop Parkinson's disease. It could be argued that Parkinson's disease is caused by a single major CNS insult and that any progression is simply due to age related neuronal attrition of the substantia nigra. ${ }^{25}$ The olfactory defect might not progress because of the regenerative capacity of nasal olfactory neurons.

An alternative hypothesis could be constructed around the finding that some patients with Parkinson's disease exhibit a defect in the $P-450$ cytochrome CYP2D6-debrisoquine hydroxylase gene. ${ }^{26}$ Mammalian $P-450$ dependent oxygenases provide a central line of defence against exogenous toxins and it has been shown that the risk of Parkinson's disease is more than doubled for those with a P-450 genetic polymorphism associated with deficient debrisoquine metabolism. The high concentration of $P-450$ in hepatic microsomes is well known and it has been shown that microsomes in the olfactory epithelium of, for example, the $\mathrm{rat}^{27}$ and rabbit $^{28}$ have high concentrations of $P-450$, sometimes in excess of those in the liver depending on the particular subtype. The olfactory bulb of the monkey has particularly high concentrations of $P-450$ compared with other parts of its brain. There seem to be variable concentrations of $P-450$ in the rest of the CNS but most areas are incompletely characterised. Numerous volatile compounds are readily absorbed by the nasal mucosa. ${ }^{29}$ Many non-volatile materials such as environmental pollutants can reach the nasal mucosa, probably by adsorption on to small particles in the air that deposit on the nasal epithelium. ${ }^{30}$ Compounds absorbed by the nasal mucosa are actively metabolised in situ, sometimes detoxified, or they may be activated to become more toxic or carcinogenic. ${ }^{3132}$ Compounds that have been shown to be metabolised in vitro by the nasal $P-450$ dependent monooxygenase system include nasal decongestants, essences, anaesthetics, alcohols, nicotine, cocaine, and many nasal carcinogens. ${ }^{33}$ It has been shown that herbicides such as dioxins ${ }^{34}$ or chlorthiamid, ${ }^{35}$ whether given intravenously or intraperitoneally, are selectively taken up by and harmful to the olfactory epithelium. Some compounds seem to be selectively toxic to the olfactory epithelium whereas others cause damage indirectly by formation of toxic byproducts. The CNS distribution of CYP2D6 is not known but if it were to be concentrated in the basal ganglia and olfactory pathways the regular appearance of pathology at these sites might be explained.

We conclude that patients with Parkinson's disease have a severe, apparently stable defect of smell sense which is as frequent as tremor and almost as common as bradykinesia. Why such disparate items such as movement disor- der and anosmia should occur together is perplexing. It may relate either to simple damage by an agent that enters the CNS via the nose or there may be a defective $P-450$ cytochrome system common to the olfactory and basal ganglia pathways. These two hypotheses are not necessarily mutually exclusive.

SED is funded by a grant from the United Kingdom Parkinson's Disease Society. We are grateful to Peter Sacares and Ann Petruckevitch, Institute of Neurology, for statistical support.

1 Doty RL, Deems DA, Stellar S. Olfactory dysfunction in parkinsonism: a general deficit unrelated to neurologic
signs, disease stage or disease duration. Neurology 1988; 38:1237-44

2 Kobal G, Plattig KH. Methodische Anmerkungen zur Gewinnung olfaktorischer EEG-Antworten des wachen Menschen (objektive Olfaktometrie). Z EEG-EMG 1978; 9:135-45.

3 Hawkes CH, Kobal G, Shephard B. The olfactory evoked response and evidence of disordered olfaction in multiple response and evidence of disordered olfaction in multipl

4 Chui HC, Mortimer JA, Slager U, Zarow C, Bondareff W, Webster DD. Pathological correlates of dementia in Parkinson's disease. Arch Neurol 1986;43:991-5.

5 Doty RL, Shaman P, Dann M. Development of the University of Pennsylvania smell identification test: standardised microencapsulated test of olfactory function. Physiol Behav 1984;32:489-502.

6 Hughes AJ, Daniel SE, Kilford L, Lees AJ. Accuracy of clinical diagnosis of idiopathic Parkinson's disease: a clinico-pathological study of 100 cases. $\mathcal{F}$ Neurol Neurosurg Psychiatry 1992;55:181-4.

7 Levine HL. The office diagnosis of nasal and sinus disorders using rigid nasal endoscopy. Otolaryngol Head Neck Surg 1990:102:370-3.

8 Doty RL, Stern MB, Pfeiffer C, Gollomp SM, Hurtig HI. Bilateral olfactory dysfunction in early stage treated and untreated idiopathic Parkinson's disease. $₹$ Neurol Neurosurg Psychiatry 1992;55:138-42.

9 Quinn NP, Rossor MN, Marsden CD. Olfactory threshold in Parkinson's disease. $\mathcal{F}$ Neurol Neurosurg Psychiatry 1987;50:88-9.

10 Amsterdam JD, Gregg Settle R, Doty RL, Abelman E, Winookur A. Taste and smell perception in depression. Biol Psychiatry 1987;22:1481-5.

$11 \mathrm{Kobal} \mathrm{G}$. A new method for determination of the olfactory and the trigeminal nerve's dysfunction: olfactory (OEP) and chemical somatosensory (CSEP) evoked potentials. In: A Rothenberger, ed. Event related potentials in children. In: A Rothenberger, ed. Event related

12 Kobal G, Hummel G. Cerebral chemosensory evoked potentials elicited by chemical stimulation of the human olfactory and respiratory nasal mucosa. Electroencephalog Clin Neurophysiol 1988;71:241-50.

13 Kobal G, Hummel T. Olfactory evoked potentials in humans. In: Getchell TV, Doty RL, Bartoshuk, Snow JB eds. Smell and taste in health and disease. New York Raven Press, 1991;13:269-70.

14 Doty RL, Bromley SM, Stern MB. Olfactory testing as an aid in the diagnosis of Parkinson's disease: development of optimal discrimination criteria. Neurodegeneration 1995;4:93-7.

15 Amoore JE, Pelosi P, Forrester LJ. Specific anosmias to 5androst-16-en-3-one and -pentadecalactone: the urinous and musky primary odours. Chemical Senses and Flavor 1977;2:401-25.

16 Pinching AJ, Døving KB. Selective degeneration in the rat olfactory bulb following exposure to different odours. Brain Res 1974;82:195-204.

17 Hoehn M, Yahr MD. Parkinsonism: onset, progression and mortality. Neurology 1967;17:427-42.

8 Daniel SE, Hawkes CH. Preliminary diagnosis of Parkinson's disease using olfactory bulb pathology [letter]. Lancet 1992;340:186.

19 Esiri MM, Wilcock GK. The olfactory bulbs in Alzheimer's disease. F Neurol Neurosurg Psychiatry 1984;47:56-60.

20 Mann DMA, Tucker CM, Yates PO. Alzheimer's disease: an olfactory connection? Mech Ageing Dev 1988;42: $1-15$.

21 Yoshimura N. Olfactory bulb involvement in Pick's disease. Acta Neuropathologica 1988;77:202-5.

22 Tomlinson AH, Esiri MM. Herpes simplex encephalitis: immuno-histological demonstration of spread of virus via immuno-histological demonstration of spread of virus via

23 Shipley MT. Transport of molecules from nose to brain: transneuronal anterograde and retrograde labelling in the rat olfactory system by wheatgerm agglutin-horseradish peroxidase applied to the nasal epithelium. Brain Res Bull 1985;15:129-42.

24 Buxton PH, Hayward M. Polyneuritis cranialis associated with industrial trichloroethylene exposure. $\mathcal{f}$ Neurol Neurosurg Psychiatry 1967;30:511-8.

25 Calne DB, Eisen A, McGeer E, Spencer PS. Alzheimer's disease, Parkinson's disease and motor neurone disease abiotrophic interaction between ageing and environment? Lancet 1986;ii: 1067-70 
26 Smith CAD, Gough AC, Leigh PN, Summers B, et al. Debrisoquine hydroxylase gene polymorphism and sus-
ceptibility to Parkinson' disease. Lancet 1992;339: ceptibility

27 Hext PM, Lock EA. The accumulation and metabolism of 3-trifluoromethylpyridine by rat olfactory and hepatic tissues. Toxicology 1992;72:61-75.

28 Ding $X$, Coon MJ. Immunochemical characterisation of multiple forms of cytochrome $\mathrm{P}-450$ in rabbit nasal microsomes and evidence for tissue specific expression of P-450s NMa and NMb. Cellular Pharmacology 1990; 37:489-96.

29 Stott WT, Ramsey JC, McKenna MJ. Absorption of chemical vapours by the upper respiratory tract of rats. In: CS Barrow, ed. Toxicology of the nasal passages. Washington, DC: Hemisphere Publishing Corporation, 1986:191-210.

30 Schlesinger RB. Comparative deposition of inhaled aerosols in experimental animals and humans: a review. $f$ Toxicol Environ Health 1985;15:197-214.

31 Bond JA. Bioactivation and biotransformation of xenobi- otics in rat nasal tissue. In: CS Barrow, ed. Toxicology of the nasal passages. Washington DC: Hemisphere Publishing Corporation, 1986:249-61.

32 Dahl AR. Possible consequences of cytochrome P-450 dependent monooxygenases in nasal tissues. In: CS Barrow, ed. Toxicology of the nasal passages. Washington DC: Hemisphere Publishing Corporation, 1986:263-73.

33 Dahl AR. The effect of cytochrome P-450-dependent metabolism and other enzyme activities in olfaction. In: Margolis FL, Getchell TV, eds. Molecular neurobiology of the olfactory system. New York: Plenum Press, 1988: $51-70$

34 Gillner M, Brittebo EB, Brandt I, Soderkvist P, Appelgren L-E, Gustafsson J-A. Uptake and specific binding of 2,3,7,8-tetrachlorodibenzo-p-dioxin in the olfactory mucosa of mice and rats. Cancer Res $1987 ; 47 ; 4150-9$.

35 Brittebo EB, Eriksson VF, Bakke J and Brandt I. Toxicity of 2,6-dichlorothiobenzamide (chlorthiamid) and 2,6Fundam Appl Toxicol 1991;17:92-102.

\section{,

